\title{
Depression and Somatization in Refractory Lateral Epicondylitis
}

\author{
Eda GÜRÇAY1 ${ }^{1}$, Arif Uğur TAMKAN² ${ }^{\mathbb{D}}$, Özgür Zeliha KARAAHMET²(D, \\ Yasemin TOMBAK ${ }^{2}$ D, Şükran GÜZEL ${ }^{2}$ iD, Aytül ÇAKCI ${ }^{2}$ D \\ ${ }^{1}$ Department of Physical Medicine and Rehabilitation, Gaziler Physical Medicine and Rehabilitation \\ Training and Research Hospital, Ankara, Turkey \\ ${ }^{2}$ Department of Physical Medicine and Rehabilitation, Dışkapı Yıldırım Beyazıt Education and Research Hospital, Ankara, Turkey
}

\begin{abstract}
Objectives: This study aims to present two major psychological factors, namely depression and somatization, which may occur with high probability in patients with refractory lateral epicondylitis (LE).

Patients and methods: This cross-sectional study included 36 patients (11 males, 25 females; mean age $42.6 \pm 8.09$ years; range 26 to 60 years) diagnosed as refractory LE. Duration of symptoms was $>6$ months. Each patient completed the Beck Depression Inventory and the Symptom Checklist-90-Revised test evaluating psychosocial status and somatization, respectively.

Results: Depression was found in $24(66.6 \%)$ (moderate in 15 [41.7\%] and mild in 9 [25\%]) and somatization was found in 28 (77.8\%) patients. Depression and somatization were significantly more common in females than males ( $p=0.02$ and $p=0.04$, respectively).

Conclusion: Depression and somatization may occur frequently in refractory LE patients, particularly in females. Both physical and psychological assessment tools should be incorporated into the clinical evaluation while psychological support should be included in the treatment of refractory LE.

Keywords: Depression; lateral epicondylitis; psychosocial status; somatization.
\end{abstract}

Lateral epicondylitis (LE) is a common musculoskeletal condition affecting the wrist extensor tendons, which may be related to occupation or psychological/physiological factors. ${ }^{1}$ Although psychological factors explain a large part of the variability in disability, limited attention has been paid to the potential prognostic value of psychosocial factors. ${ }^{2}$

Depression is usually associated with chronic pain and may affect patients' prognosis while preventing recovery. ${ }^{3}$ Somatization is defined as the presence of physical complaints that cannot be explained by any somatic disease. ${ }^{4}$ In this study, we aimed to present two major psychological factors, namely depression and somatization, which may occur with high probability in patients with refractory LE.

\section{PATIENTS AND METHODS}

This cross-sectional study was conducted at Ankara Dışkapı Education and Research Hospital between January 2015 and February 2016 and comprised 36 patients (11 males, 25 females; mean age $42.6 \pm 8.09$ years; range 26 to 60 years) diagnosed as refractory LE. Duration of symptoms was $>6$ months. The study protocol was approved by the Ankara Dışkapı Education

Received: August 07, 2018 Accepted: November 20, 2018 Published online: January 28, 2019

Correspondence: Eda Gürçay, MD. SBÜ Gaziler Fizik Tedavi ve Rehabilitasyon Eğitim ve Araştırma Hastanesi, Fizik Tedavi ve Rehabilitasyon Kliniği, 06800 Çankaya, Ankara, Turkey. Tel: +90 312 - 3261072 e-mail: dredagurcay@gmail.com

\section{Citation:}

Gürçay E, Tamkan AU, Karaahmet ÖZ, Tombak Y, Güzel Ş, Çakcı A. Depression and somatization in refractory lateral epicondylitis. Arch Rheumatol 2019;34(4):367-370. 


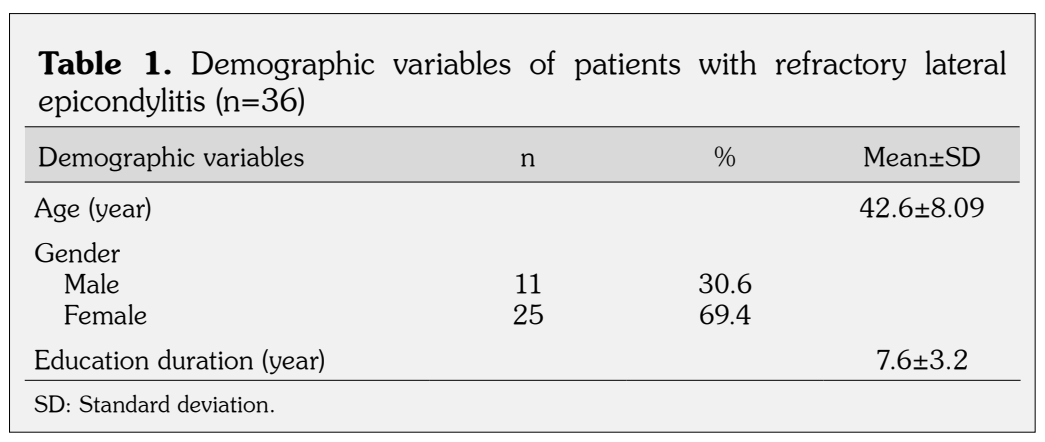

Table 2. Results for occupational predisposing and psychological factors according to sex

\begin{tabular}{lcccccc}
\hline & \multicolumn{3}{c}{ Female } & & \multicolumn{3}{c}{ Male } & \\
\cline { 2 - 3 } \cline { 5 - 6 } & $\mathrm{n}$ & $\%$ & & $\mathrm{n}$ & $\%$ & $p$ \\
\hline Occupational predisposing factors & 3 & 8.3 & & 10 & 27.7 & $<0.001$ \\
Depression & 20 & 55.5 & & 4 & 11.1 & 0.02 \\
Somatization & 22 & 61.1 & & 6 & 16.6 & 0.04 \\
\hline $\begin{array}{l}\text { Statistical significance of differences was assessed using chi-square test for nominal variables or Mann-Whitney U test for } \\
\text { continuous variables. }\end{array}$
\end{tabular}

and Research Hospital Ethics Committee (number 42/03). A written informed consent was obtained from each patient. The study was conducted in accordance with the principles of the Declaration of Helsinki.

The diagnosis of LE was established upon failure of at least six months of conservative treatment. Exclusion criteria were previous elbow surgery, joint limitations, or symptoms suggesting radicular, neurological, or systemic arthritic conditions. Patients were questioned in terms of occupational predispositions such as physically demanding work including high repetition, handarm vibration, or awkward posture.

A screening instrument, Beck Depression Inventory, was used to assess psychosocial status. ${ }^{5}$ Evaluation of patients for somatization was performed by the Turkish version of the Symptom Checklist-90-Revised test. ${ }^{6}$ The tests were performed by the same psychologist.

\section{Statistical analysis}

The IBM SPSS version 20.0 software (IBM Corp., Chicago, Illinois, USA) was used for statistical analysis. Statistical significance of differences was assessed using the Chi-square test for nominal variables or Mann-Whitney $\mathrm{U}$ test for continuous variables. Statistical significance level was set at $p<0.05$.

\section{RESULTS}

Demographic data of the patients were demonstrated in Table 1 . Totally 13 patients (10 males [27.7\%] and three females [8.3\%]) had occupational predispositions: three patients were housewives who meticulously cleaned the house every day, three were computer users for more than two hours per day, one was an automobile assembly worker, and six were workers of heavy manual labor. The number of males with occupational predisposition was significantly higher than females $(p<0.001)$ (Table 2).

There were 24 patients (66.6\%) with depression (moderate in 15 [41.7\%] and mild in 9 [25\%]) and 28 patients (77.8\%) with somatization, while 22 patients (61.1\%) had both psychological components. Depression and somatization were significantly more common in females than males $(p=0.02$ and $p=0.04$, respectively) (Table 2).

\section{DISCUSSION}

To our knowledge, the present study is the first to concurrently investigate the existence of two important psychological factors, namely depression and somatization, in patients with 
refractory LE. Our results illustrated that depression and somatization were present in the majority of patients, particularly in females, with refractory LE.

Some studies have revealed associations between occupational risk factors and LE particularly in meat cutters, construction workers, and housewives. ${ }^{7-9}$ In this study, 13 patients had occupational predispositions with forceful and repetitive hand activities. Repetitive work does not appear to be a risk factor on its own; however, there is a relationship between combined risk factors such as force, posture, and vibration. The increased rate of LE in females and housewives, computer users or workers may be due to the inclusion of various home or job activities that require maximum use of wrist extensor muscles causing the rupture of muscles.

This study showed that the majority of patients had depression and somatization, or both of these psychological components. In cross-sectional studies in which depressive symptoms were assessed among cases with upper limb pain, depression has been thought to partially reflect the long-term outcomes of chronic upper limb pain. ${ }^{5,6}$ Aben et al. ${ }^{12}$ demonstrated that patients with LE were less agreeable, had more depressive feelings, and were more perfectionists than healthy controls. They emphasized that this may lead to negative consequences and weaken selfesteem when efforts continue and are never satisfied. ${ }^{7}$ Symptoms related to anxiety and depression (e.g., reduced concentration, lack of motivation, chronic fatigue, poor sleep, and negative mood) may reduce the benefit to be obtained from prescribed treatment and rehabilitation programs. Therefore, a good relationship between the physiatrist and patient is essential to bring the therapy to a successful conclusion..$^{7,8}$ Consistent and predominant role of several modifiable psychological factors in disability suggests that patients may benefit from a multidisciplinary approach that optimizes mindset and coping strategies. ${ }^{9}$

The main limitation of our study is the small sample size that might not be large enough to draw robust results; second limitation, this is a single-center study which might be subject to regional bias. Therefore, studies with larger sample size are required to further validate the findings of this study.

Since occupational predispositions may lead to LE, workload modification should be considered, particularly in manually intensive work tasks. Depression and somatization, or even both may occur frequently in patients with LE, particularly in females. Thus, a multidisciplinary approach including both physical and psychological assessments should be incorporated into the clinical evaluation while psychological support should be included in the treatment of refractory LE.

\section{Declaration of conflicting interests}

The authors declared no conflicts of interest with respect to the authorship and/or publication of this article.

\section{Funding}

The authors received no financial support for the research and/or authorship of this article.

\section{REFERENCES}

1. Treaster DE, Burr D. Gender differences in prevalence of upper extremity musculoskeletal disorders. Ergonomics 2004;47:495-526.

2. Ring D, Kadzielski J, Malhotra L, Lee SG, Jupiter JB. Psychological factors associated with idiopathic arm pain. J Bone Joint Surg [Am] 2005;87:374-80.

3. Singh JA, Lewallen DG. Medical and psychological comorbidity predicts poor pain outcomes after total knee arthroplasty. Rheumatology (Oxford) 2013;52:916-23.

4. Ford CV. The somatizing disorders. Psychosomatics 1986;27:327-31.

5. Beck AT, Ward CH, Mendelson M, Mock J, Erbaugh J. An inventory for measuring depression. Arch Gen Psychiatry 1961;4:561-71.

6. Dag I. Belirti Tarama Listesi (SCL-90-R)'nin üniversite öğrencileri için güvenirliği ve geçerliği. Türk Psikiyatri Dergisi 1991;1:5-12.

7. Kurppa K, Viikari-Juntura E, Kuosma E, Huuskonen $\mathrm{M}$, Kivi P. Incidence of tenosynovitis or peritendinitis and epicondylitis in a meat-processing factory. Scand J Work Environ Health 1991;17:32-7.

8. Kopf T, von Feder T, Karmaus W. Risks for musculoskeletal disorders of the low back, the shoulders, the elbows and the wrist in bricklayers. In: Hogstedt C, Reuterwall C, editors. Progress in Occupational Epidemiology. Amsterdam: Elsevier Scientific Publishers; 1988. p. 219-22. 
9. Dhakal S, Acharya T, Gautam S, Upadhyay N, Dhakal S. Diagnosis and Management Pattern of Lateral Epicondylitis in a Tertiary Care Center. JNMA J Nepal Med Assoc 2015;53:231-4.

10. Spence SH. Psychopathology among acute and chronic patients with occupationally related upper limb pain versus accident injuries of the upper limbs. Austr Psychol 1990;25:293-305.

11. Alizadehkhaiyat O, Fisher AC, Kemp GJ, Frostick SP. Pain, functional disability, and psychologic status in tennis elbow. Clin J Pain 2007;23:482-9.
12. Aben A, De Wilde L, Hollevoet N, Henriquez C, Vandeweerdt $\mathrm{M}$, Ponnet $\mathrm{K}$, et al. Tennis elbow: associated psychological factors. J Shoulder Elbow Surg 2018;27:387-92.

13. Mallows A, Debenham J, Walker T, Littlewood C. Association of psychological variables and outcome in tendinopathy: a systematic review. Br J Sports Med 2017;51:743-8.

14. Das De S, Vranceanu AM, Ring DC. Contribution of kinesophobia and catastrophic thinking to upperextremity-specific disability. J Bone Joint Surg [Am] 2013;95:76-81. 